\title{
Unusual traits of cis and trans-2,3-dibromo-1,1-dimethyl- indane on the way from 1,1-dimethylindene to 2-bromo-, 3-bromo-, and 2,3-dibromo-1,1-dimethylindene
}

\author{
Rudolf Knorr ${ }^{*}$, David S. Stephenson, Ernst Lattke, Petra Böhrer and Jakob Ruhdorfer
}

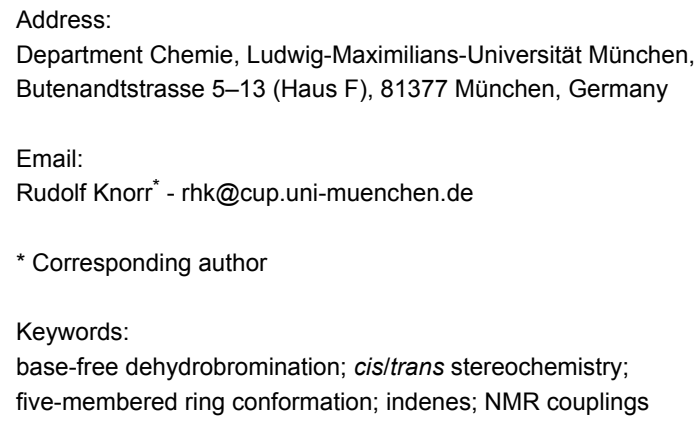

Beilstein J. Org. Chem. 2016, 12, 1178-1184. doi:10.3762/bjoc.12.113

Received: 08 February 2016

Accepted: 20 May 2016

Published: 10 June 2016

Associate Editor: J. N. Johnston

(c) 2016 Knorr et al; licensee Beilstein-Institut. License and terms: see end of document.

\begin{abstract}
Do not rely on the widely accepted rule that vicinal, $\mathrm{sp}^{3}$-positioned protons in cyclopentene moieties should always have more positive ${ }^{3} J$ NMR coupling constants for the $c i s$ than for the trans arrangement: Unrecognized exceptions might misguide one to wrong stereochemical assignments and thence to erroneous mechanistic conclusions. We show here that two structurally innocent-looking 2,3-dibromo-1,1-dimethylindanes violate the rule by means of their values of ${ }^{3} J(\mathrm{cis})=6.1 \mathrm{~Hz}$ and ${ }^{3} J(\operatorname{trans})=8.4 \mathrm{~Hz}$. The stereoselective formation of the trans diastereomer from 1,1-dimethylindene was improved with the tribromide anion $\left(\mathrm{Br}_{3}{ }^{-}\right)$as the brominating agent in place of elemental bromine; the ensuing, regiospecific $\mathrm{HBr}$ elimination afforded 3-bromo-1,1-dimethylindene. The addition of elemental bromine to the latter compound, followed by thermal $\mathrm{HBr}$ elimination, furnished 2,3-dibromo-1,1-dimethylindene, whose $\mathrm{Br} / \mathrm{Li}$ interchange reaction, precipitation, and subsequent protolysis yielded only 2-bromo-1,1-dimethylindene.
\end{abstract}

\section{Introduction}

The basic mechanistic features of competing suprafacial and antarafacial additions of elemental bromine to an olefin are reasonably well established [1-3]. With indene as a cyclic olefin, the major product trans-1,2-dibromoindane was formed through antarafacial addition; the accompanying cis diastereomer resulted through the suprafacial bromine addition and rarely [4] exceeded $30 \%$ of the diastereomeric trans/cis product mixture. For the cis/trans assignments, common wisdom [5] commends the simple criterion that three-bond NMR coupling constants $\left({ }^{3} J_{\mathrm{H}, \mathrm{H}}\right)$ should be more positive for a cis than for a trans relationship of the vicinal, $\mathrm{sp}^{3}$-positioned protons in fivemembered rings. Indeed, cis-1,2-dibromoindane displayed ${ }^{3} J(1-\mathrm{H}, 2-\mathrm{H})=5.0 \mathrm{~Hz}$, whereas the trans diastereomer exhibited ${ }^{3} J(1-\mathrm{H}, 2-\mathrm{H})=1.3 \mathrm{~Hz}[6]$. However, we report here on the 
closely related trans diastereomer of 2,3-dibromo-1,1-dimethylindane (trans-1) whose grossly deviating value of ${ }^{3} J(2-\mathrm{H}, 3-\mathrm{H})$ $=8.4 \mathrm{~Hz}$ violates the above ${ }^{3} J_{\mathrm{H}, \mathrm{H}}$ rule.

\section{Results and Discussion}

The addition of elemental bromine to 1,1-dimethylindene (2, see Supporting Information File 1) in $\mathrm{CCl}_{4}$ as the solvent afforded a 7:3 mixture of trans-1 and cis-1 (Scheme 1). A more useful 9:1 mixture was obtained through the slow titration of a well-stirred chloroform solution of equimolar amounts of $\mathbf{2}$ and tetraethylammonium bromide with elemental bromine in chloroform. Such a higher trans selectivity is typical of the very rapidly [1] formed tribromide anion $\left(\mathrm{Br}_{3}{ }^{-}\right)$as the reactive species.

What kind of evidence supports our stereochemical assignments of trans-1 and cis-1? Although the three-bond NMR coupling constant ${ }^{3} J(2-\mathrm{H}, 3-\mathrm{H})=6.1 \mathrm{~Hz}$ of cis-1 is close to normal, trans $\mathbf{- 1}$ exhibits the abnormally high value of $8.4 \mathrm{~Hz}$ (compare that with $1.3 \mathrm{~Hz}$ for trans-1,2-dibromoindane [6]), violating the commonly accepted ${ }^{3} J_{\mathrm{H}, \mathrm{H}}$ rule that was mentioned in the Introduction. A more reliable criterion may be visualized from the envelope shape (expected puckering ca. $22-33^{\circ}$ ) of the cyclopentene parts of 1 (lines 2 and 3 of Scheme 1): the distance between two vicinal, $\mathrm{sp}^{3}$-positioned protons in indanes clearly must be substantially longer for the pseudodiaxial (2ax-H,3ax-H) trans than for the pseudoaxial/pseudoequatorial
(2ax-H,3eq-H) cis interproton relationships. Such distances may be estimated through nuclear magnetic Overhauser enhancements (NOE). As expected if trans-1 populates predominantly the 2ax-H,3ax-H conformation shown in Scheme 1, our onedimensional NOE difference experiments revealed an approximately eight-fold stronger enhancement of the 3-H doublet signal of cis-1 than of trans-1 on irradiation of the almost coincident two 2-H NMR doublets of the two diastereomers; this established our assignments. In addition, a two-dimensional NOESY experiment displayed a cross-peak between 3-H and one of the two 1- $\mathrm{CH}_{3}$ signals of trans-1. The necessary short distance of the involved protons can be traced to a 1,3-pseudodiaxial arrangement of $3-\mathrm{H}$ and one of the methyl groups in the 2ax-H,3ax-H conformation. Thus, a close to $160^{\circ}$ torsional relationship between the $\mathrm{C}(2)-\mathrm{H}$ and $\mathrm{C}(3)-\mathrm{H}$ bonds gives rise to the surprisingly high value of ${ }^{3} J(2-\mathrm{H}, 3-\mathrm{H})=8.4 \mathrm{~Hz}[7,8]$. The hyperconjugative interaction of this pseudoaxial $\mathrm{C}(3)-\mathrm{H}$ bond with the aromatic $\pi$ system causes a long-range (hence weak) magnetic coupling $(J=0.7 \mathrm{~Hz}$ ) between $3-\mathrm{H}$ and (presumably) 4-H in trans-1 (but not found in cis-1). The different conformational preference of trans-1 as compared with the methyl-free trans-1,2-dibromoindene $\left({ }^{3} J=1.3 \mathrm{~Hz}[6]\right)$ may obviously be ascribed to the two 1-Me groups [9]. In accord with the pseudoaxial C(3)-H bond, HMBC (hetero multiple bond correlation) cross peaks of 3-H in trans-1 were absent with both $\mathrm{C}-1$ and $\mathrm{C}-7 \mathrm{a}$. On the other hand, the corresponding cross peaks were strong in cis-1 between 3eq-H and both $\mathrm{C}-1$ and $\mathrm{C}-7 \mathrm{a}$,

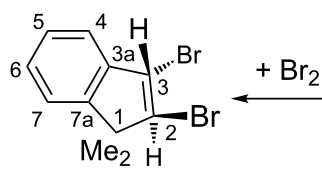

trans-1

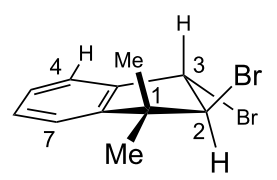

$2 \mathrm{ax}-\mathrm{H}, 3 \mathrm{ax}-\mathrm{H}$
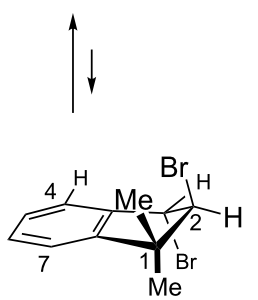

2eq-H, 3eq-H

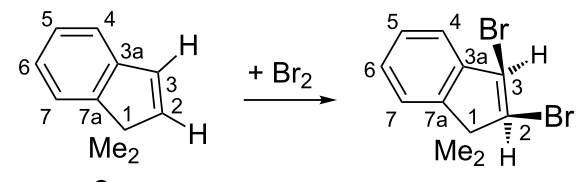

2

cis- 1

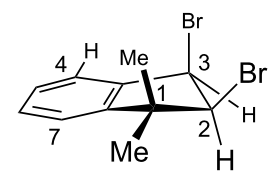

2ax-H, 3eq-H

envelope ring flipping
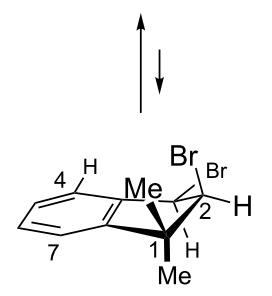

2eq-H, 3ax-H 
which indicated a significant ${ }^{3} J_{\mathrm{C}, \mathrm{H}} \mathrm{NMR}$ coupling via the intervening single bonds in their roughly coplanar arrangement shown in Scheme 1. It may also be noticed that the small $\mathrm{C}(2)-\mathrm{H} / \mathrm{C}(3)-\mathrm{H}$ torsional angles in either one of the two cis-1 conformations are of similar sizes and do not permit a conformational differentiation. On the other hand, the close to $90^{\circ}$ torsional angle between $3-\mathrm{H}$ and $2-\mathrm{H}$ in the 2 eq- $\mathrm{H}, 3$ eq-H conformation of trans-1 would imply an almost vanishing ${ }^{3} J_{\mathrm{H}, \mathrm{H}}$ value, in contrast with the observed value of $8.4 \mathrm{~Hz}$ that is explained by the predominant $2 \mathrm{ax}-\mathrm{H}, 3 \mathrm{ax}-\mathrm{H}$ conformation.

Distillation of the trans/cis product mixture led to some enrichment of the thermally more stable diastereomer trans-1 due to the "base-free" $\mathrm{HBr}$ elimination from cis-1 with formation of 2-bromo-1,1-dimethylindene (4 in Scheme 2) [10]. We observed a less distinct kinetic preference in the corresponding base-induced processes: In di(2-methoxyethyl) ether (diglyme) as the solvent, a substoichiometric amount of $\mathrm{KO} t$-Bu (potassium tert-butoxide) reacted faster with cis-1 than with trans-1 by a factor of roughly 9 at room temperature (rt). With an excess ( $>2$ equiv) of $\mathrm{KO} t$-Bu, both of these weakly exothermic $\mathrm{HBr}$ elimination reactions were completed within less than 30 min. With $\mathrm{KO} t$-Bu (at $\mathrm{rt}$ ) or $\mathrm{KOEt}\left(\right.$ at $50{ }^{\circ} \mathrm{C}$ ) but not with $\mathrm{NEt}_{3}$ (no reaction at $\mathrm{rt}$ ), the exclusive formation of 3-bromo1,1-dimethylindene (3) from trans-1 and of $\mathbf{4}$ from cis-1 became evident through the similarity of the emerging $3 / 4$ ratios as compared with the trans-1/cis-1 ratios in the employed mixtures [11]. This regiospecificity is readily understandable since trans-1 has no anti relationship of vicinal $\mathrm{Br}$ and $\mathrm{H}$ available (Scheme 1), whereas each cis-1 conformer holds a pseudodiaxial, vicinal $\mathrm{Br} / \mathrm{H}$ anti relationship and hence is (presumably) able to react somewhat faster.

We abstained from separating trans-1 and cis-1 since the availability of two different mixtures facilitated the NMR assignments and because any cis-1/trans $\mathbf{- 1}$ mixture or the ensuing $\mathbf{3} / \mathbf{4}$ mixtures may be used for preparing 2,3-dibromo-1,1-dimethylindene (7). Both 3 and 4 can add elemental bromine and the adducts (5 or $\mathbf{6}$, respectively) eliminated $\mathrm{HBr}$ either spontaneously (5) or in the presence of $\mathrm{KO} t-\mathrm{Bu}$ or $\mathrm{NEt}_{3}(6)$ at $\mathrm{rt}$ to furnish the same product 7 . We found through NOESY and HMBC analyses that the thermally more stable tribromide 6 populates the conformation which has a pseudoaxial 3-H (and hence a pseudoequatorial 3-Br) orientation (like trans-1). Therefore, the unusually high thermolability of $\mathbf{5}$ seemed to be due to the unavoidable presence of one pseudoaxial $\mathrm{C}(3)-\mathrm{Br}$ bond [12]. If so, the hitherto unknown 3,3-dibromo-1,1-dimethylindane (8) might also be prone to such thermal $\mathrm{HBr}$ elimination. For comparison, treatment of 1,1-dimethylindane (9) with one equivalent of $N$-bromosuccinimide (NBS) furnished the expected 3-bromo-1,1-dimethylindane (see Supporting

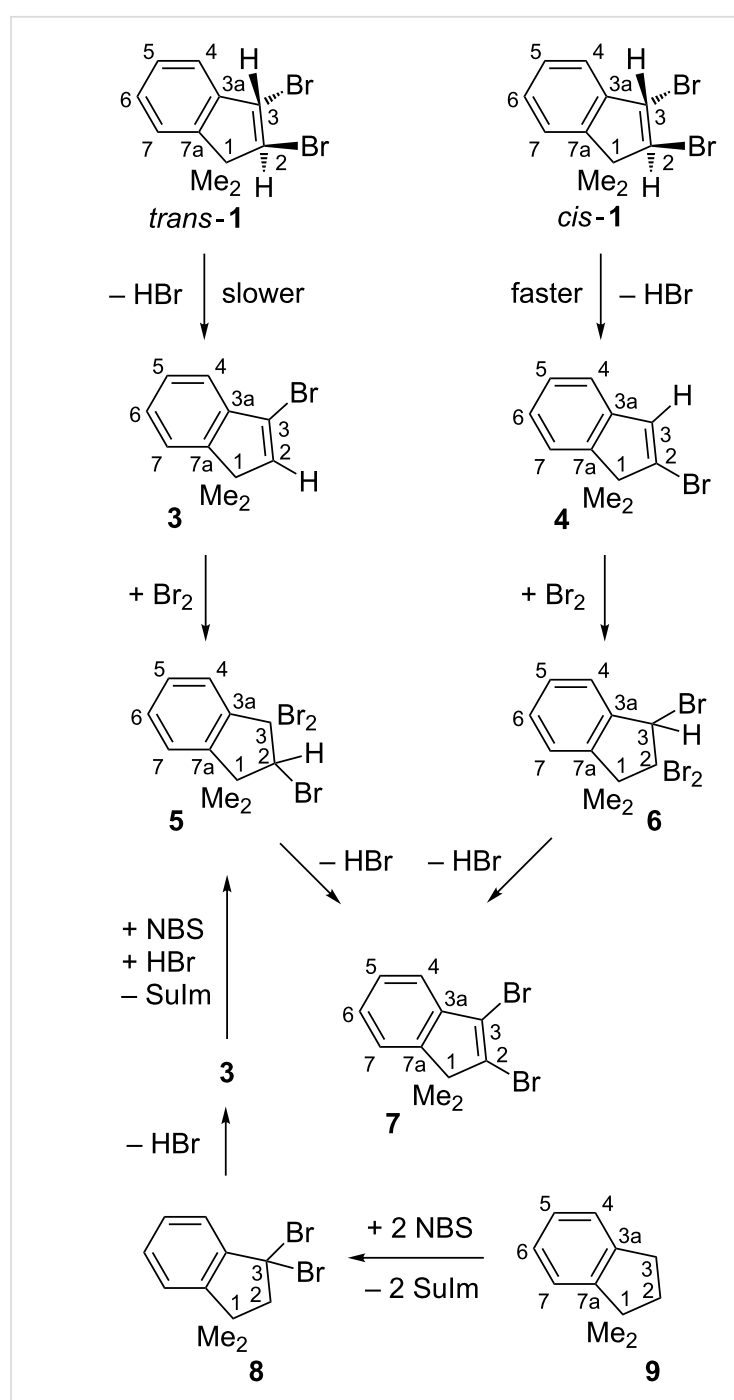

Scheme 2: The ways to 2-bromo- (4), 3-bromo- (3), and 2,3-dibromo1,1-dimethylindene (7); Sulm = succinimide, NBS = N-bromosuccinimide, $\mathrm{Me}=$ methyl.

Information File 1), which decomposed already on distillation to yield 1,1-dimethylindene (2). With two equivalents of NBS, however, $\mathbf{9}$ afforded a mixture of $\mathbf{3}$ and $\mathbf{7}$ through the following sequence in the bottom part of Scheme $2: \mathbf{9} \rightarrow \mathbf{8} \rightarrow \mathbf{3} \rightarrow \mathbf{5} \rightarrow \mathbf{7}$. Under these conditions, the spontaneous $\mathrm{HBr}$ elimination from 8 had produced $\mathbf{3}$, which added $\mathrm{Br}_{2}$ to generate the thermolabile tribromide $\mathbf{5}$, whose $\mathrm{HBr}$ elimination gave 7; the required $\mathrm{Br}_{2}$ was visible in the weakly brownish gas phase and had been provided through the well-known reaction of $\mathrm{HBr}$ with the accompanying NBS. Consequently, three equivalents of NBS would be necessary for obtaining 7 in a maximum yield. This encouraged us to reflux 9 in $\mathrm{CCl}_{4}$ with NBS (4 equiv), which furnished mainly 7 along with succinimide (3.6 equiv) and remnant NBS ( 0.4 equiv). As a side-reaction, the slower thermal $\mathrm{HBr}$ elimination from the intermediate 3-bromo-1,1-dimethylindane (see Supporting Information File 1) generated 
1,1-dimethylindene (2), whose in situ bromination furnished 1 (ca. 1\%) in a trans/cis ratio of ca. 3:2. Since both dibromides trans $\mathbf{- 1}$ and cis-1 were stable under the reaction conditions and would distil together with 7, they were destroyed through $\mathrm{HBr}$ elimination by $\mathrm{KO} t-\mathrm{Bu}$ (or $\mathrm{KOH}$ in $\mathrm{EtOH}$ ) to produce the monobromides $\mathbf{3}$ and $\mathbf{4}$. It may be noticed that $\mathbf{4}$ (from cis-1) cannot have been an intermediate in the initial step of the above "base-free" conversion of 9 to 7 , since 4 would generate the thermally stable tribromide $\mathbf{6}$ that was not detected in the initial product mixture of $\mathbf{1}$ and $\mathbf{7}$.

For practical purposes, 7 may be useful as an alternative starting material in place of 2,3-diiodo-1,1-dimethylindene that had been employed $[13,14]$ in cross-coupling studies. We actually used crude 7 as follows for a first specific route to 2-bromo-1,1dimethylindene (4). The rapid $\mathrm{Br} / \mathrm{Li}$ interchange reaction of 7 in hexane as the solvent with $n$-butyllithium ( $n$-BuLi) ocurred predominantly at the 3-position of 7 with formation of 2-bromo-3lithio-1,1-dimethylindene (10, Scheme 3). In the absence of cycloalkanes or benzene from the hydrocarbon solvent, rather concentrated mixtures of 7 and $n$-BuLi slowly deposited unsolvated $\mathbf{1 0}$, which opened the possibility of purifying $\mathbf{1 0}$ through simple washings with dry pentane under inert gas cover. Like the related 3-chloro-2-lithio-1,1-dimethylindene [15], 10 did not eliminate LiHal at rt, so that its final hydrolytic work-up provided clean 4 even from moderately contaminated 7 . Due to a well-known mixing problem [16,17], this final protolysis will be successful only in the absence (or at least after an adequate washing-out) of residual $n$-BuLi: Since protonation of $n$-BuLi and $\mathbf{1 0}$ is comparably rapid, a local depletion of the added proton source will leave the generated portion of $\mathbf{4}$ together with remnant $n-\mathrm{BuLi}$, so that a very rapid $\mathrm{Br} / \mathrm{Li}$ interchange reaction of 4 with $n$-BuLi will produce 1,1-dimethyl-2-lithioindene, whose protolysis forms 1,1-dimethylindene (2).

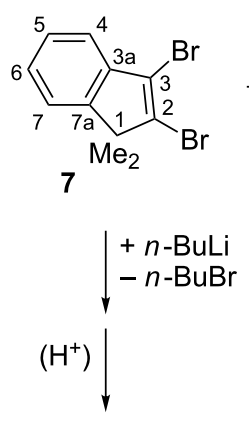

3 and $4(1: 2)$

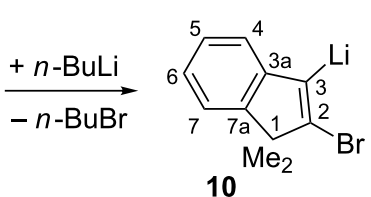

10

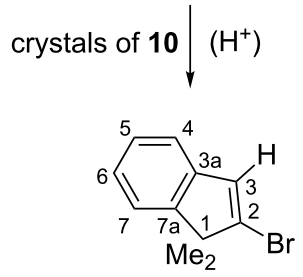

4 only

Scheme 3: Unsolvated 2-bromo-3-lithio-1,1-dimethylindene (10) precipitated from the reaction mixture of 7 with $n$-BuLi in hexane; after purification, $\mathbf{1 0}$ provided $\mathbf{4}$ only; $\mathrm{Me}=$ methyl.

\section{Conclusion}

Cis/trans differentiation in the saturated part of cyclopentene moieties should be based on ${ }^{1} \mathrm{H}$ nuclear magnetic Overhauser enhancements rather than on the magnitudes of vicinal cis and trans ${ }^{3} J_{\mathrm{H}, \mathrm{H}} \mathrm{NMR}$ coupling constants which are not always reliable. The deceivingly high value of $8.4 \mathrm{~Hz}$ in trans-2,3dibromo-1,1-dimethylindane (trans-1) is explained in this work by a preferentially populated envelope conformation with pseudoequatorial 2-Br and hence pseudodiaxial 2-H and 3-H. The alternative (incorrect) stereoassignment (“cis-19" in reference [8] and "cis-33" in reference [7] for the presently analyzed trans-1) would have misguided us to claim erroneously that we discovered a most unusual, highly cis selective olefin bromination.

What else may appear unusual with $\mathbf{1}$ and its congeners? Trans $\mathbf{- 1}$ and cis-1 undergo regiospecific $\mathrm{HBr}$ eliminations even in the absence of bases, cis-1 does so more rapidly than trans $\mathbf{- 1}$. The products 3 and $\mathbf{4}$, respectively, can serve as precursors for the same product 2,3-dibromo-1,1-dimethylindene (7). Exploiting the unusually high inclination of 3,3-di- (8) and 2,3,3-tribromo-1,1-dimethylindane (5) toward "base-free" $\mathrm{HBr}$ elimination at close to rt [12], we were able to convert 1,1-dimethylindane (9) with NBS directly to 7. The preparation of clean 2-bromo-1,1-dimethylindene (4) became possible through purification and hydrolysis of crystalline 2-bromo-3-lithio-1,1dimethylindene (10).

\section{Experimental}

General remark. ${ }^{1} \mathrm{H}$ and ${ }^{13} \mathrm{C}$ NMR chemical shifts $\delta$ (ppm) were referenced to internal tetramethylsilane.

2,3-Dibromo-1,1-dimethylindane (1). a) Trans-1: Tetraethylammonium bromide (18.32 g, $87.2 \mathrm{mmol}$ ) was dissolved with magnetic stirring in a minimum volume of chloroform $(120 \mathrm{~mL})$, treated with 1,1-dimethylindene $(2,12.55 \mathrm{~g}$, $87.1 \mathrm{mmol}$, see Supporting Information File 1), and then cooled in an ice-bath. Elemental bromine (4.44 mL, $13.9 \mathrm{~g}, 87.1 \mathrm{mmol})$ in chloroform $(40 \mathrm{~mL})$ was added dropwise at such a rate that each drop was quickly decolorized (65 min). After warm-up to rt within the next hour, the mixture was immediately shaken with aqueous $\mathrm{Na}_{2} \mathrm{CO}_{3}(2 \mathrm{M})$ until alkaline, washed with distilled water until neutral, dried over $\mathrm{Na}_{2} \mathrm{SO}_{4}$, and concentrated. The crude material $(23.1 \mathrm{~g}, 87 \%)$ was a colorless, liquid mixture of trans-1 and cis-1 (9:1) with bp $145-149{ }^{\circ} \mathrm{C} / 11$ Torr (no data given in reference [7]).

${ }^{1} \mathrm{H} \mathrm{NMR}\left(\mathrm{CDCl}_{3}, 400 \mathrm{MHz}\right) \delta 1.22\left(\mathrm{~s}, 3 \mathrm{H}\right.$, pseudoaxial 1- $\left.\mathrm{CH}_{3}\right)$, $1.42\left(\mathrm{~s}, 3 \mathrm{H}\right.$, pseudoequatorial $\left.1-\mathrm{CH}_{3}\right), 4.35\left(\mathrm{~d},{ }^{3} J=8.4 \mathrm{~Hz}, 1 \mathrm{H}\right.$, 2-H), $5.40\left(\mathrm{dd},{ }^{3} J=8.4 \mathrm{~Hz},{ }^{4} J=0.7 \mathrm{~Hz}, 1 \mathrm{H}, 3-\mathrm{H}\right), 7.17(\mathrm{~m}, 1 \mathrm{H}$, 7-H), 7.28 (m, 1H, 5-H), 7.31 (m, 1H, 6-H), 7.41 (m, 1H, 4-H) 
ppm, assigned through HSQC, HMBC (see below), and the following NOESY correlations: $2-\mathrm{H} \leftrightarrow$ pseudoequatorial 1- $\mathrm{CH}_{3}$ $\leftrightarrow 7-\mathrm{H} \leftrightarrow$ pseudoaxial 1- $\mathrm{CH}_{3} \leftrightarrow 2-\mathrm{H}$ (very weak), 4-H $\leftrightarrow$ pseudoaxial $3-\mathrm{H} \leftrightarrow$ pseudoaxial $1-\mathrm{CH}_{3}$ (strong); ${ }^{1} \mathrm{H}$ NMR $\left(\mathrm{D}_{3} \mathrm{C}-\mathrm{C} \equiv \mathrm{N}, 200 \mathrm{MHz}\right) \delta 1.21$ and $1.43(2 \mathrm{~s}, 2 \times 3 \mathrm{H}, 2 \times$ $\left.1-\mathrm{CH}_{3}\right), 4.45$ and $5.58\left(\mathrm{AB}\right.$ system, ${ }^{3} J=8.4 \mathrm{~Hz}, 2 \times 1 \mathrm{H}, 2-\mathrm{H}$ and 3-H), ca. 7.2 (m, 7-H) ppm; ${ }^{13} \mathrm{C} \mathrm{NMR}\left(\mathrm{CDCl}_{3}, 100.6 \mathrm{MHz}\right)$ $\delta 25.77$ (pseudoequatorial 1- $\mathrm{CH}_{3}$ ), 26.98 (pseudoaxial 1- $\mathrm{CH}_{3}$ ), 46.95 (C-1), 56.61 (C-3), 68.31 (C-2), 122.16 (C-7), 125.85 (C-4), 127.94 (C-5), 129.43 (C-6), 138.70 (C-3a), 147.68 (C-7a) ppm, assigned through $\mathrm{HSQC}$ and the following ${ }^{1} \mathrm{H} /{ }^{13} \mathrm{C}$ HMBC ${ }^{3} J$ and ${ }^{2} J$ interactions. ${ }^{3} J: 2-\mathrm{H} \rightarrow$ both $1-\mathrm{CH}_{3}$, pseudoaxial $3-\mathrm{H}$ $\rightarrow$ neither C-7a nor C-1, 4-H $\rightarrow$ C-6, 7-H $\rightarrow$ C-5, both 1-CH $\rightarrow \mathrm{C}-2$ and C-7a, C-3a $\rightarrow 5-\mathrm{H}$ and 7-H, C-4 $\rightarrow$ 6-H, C-7 $\rightarrow$ $5-\mathrm{H}, \mathrm{C}-7 \mathrm{a} \rightarrow 4-\mathrm{H}$ and $6-\mathrm{H}$, pseudoaxial $1-\mathrm{CH}_{3} \rightarrow$ pseudoequatorial $1-\mathrm{CH}_{3}$, pseudoequatorial $1-\mathrm{CH}_{3} \rightarrow$ pseudoaxial $1-\mathrm{CH}_{3} ;{ }^{2} \mathrm{~J}: 2-\mathrm{H} \rightarrow \mathrm{C}-3,3-\mathrm{H} \rightarrow \mathrm{C}-2$ and $\mathrm{C}-3 \mathrm{a}$, both $1-\mathrm{CH}_{3} \rightarrow$ C-1. Anal. calcd for $\mathrm{C}_{11} \mathrm{H}_{12} \mathrm{Br}_{2}$ (304.02): C, 43.46; H, 3.98; found: C, 44.06; H, 3.92.

b) Cis-1: This was analyzed in the 3:7 mixture with trans-1 as obtained from 1,1-dimethylindene (2) through titration with elemental bromine (not $\left.\mathrm{Br}_{3}{ }^{-}\right) .{ }^{1} \mathrm{H} \mathrm{NMR}\left(\mathrm{CDCl}_{3}, 400 \mathrm{MHz}\right) \delta$ 1.33 and $1.42\left(2 \mathrm{~s}, 2 \times 3 \mathrm{H}, 2 \times 1-\mathrm{CH}_{3}\right), 4.34\left(\mathrm{~d},{ }^{3} \mathrm{~J}=6.1 \mathrm{~Hz}\right.$, $1 \mathrm{H}, 2-\mathrm{H}), 5.55\left(\mathrm{~d},{ }^{3} J=6.1 \mathrm{~Hz}, 1 \mathrm{H}, 3-\mathrm{H}\right), 7.20$ (m, 1H, 7-H), $7.27(\mathrm{~m}, 5-\mathrm{H}), 7.34(\mathrm{~m}, 6-\mathrm{H}), 7.42(\mathrm{~m}, 4-\mathrm{H}) \mathrm{ppm}$, assigned through HSQC, HMBC (see below), and the following NOESY correlations: $2-\mathrm{H} \leftrightarrow$ both $1-\mathrm{CH}_{3} \leftrightarrow 7-\mathrm{H}$, but pseudoequatorial $3-\mathrm{H} \leftrightarrow 4-\mathrm{H}$ only $\left(\right.$ not $\left.1-\mathrm{CH}_{3}\right) ;{ }^{1} \mathrm{H}$ NMR $\left(\mathrm{D}_{3} \mathrm{C}-\mathrm{C} \equiv \mathrm{N}, 200 \mathrm{MHz}\right)$ $\delta 4.54$ and $5.76\left(\mathrm{AB}\right.$ system, ${ }^{3} \mathrm{~J}=6.0 \mathrm{~Hz}, 2 \times 1 \mathrm{H}, 2-\mathrm{H}$ and $\left.3-\mathrm{H}\right)$ ppm; ${ }^{13} \mathrm{C} \mathrm{NMR}\left(\mathrm{CDCl}_{3}, 100.6 \mathrm{MHz}\right) \delta 26.07$ and $26.58(2 \times$ 1- $\left.\mathrm{CH}_{3}\right), 47.23$ (C-1), 55.70 (C-3), 62.07 (C-2), 123.00 (C-7), 125.56 (C-4), 127.83 (C-5), 130.00 (C-6), 139.30 (C-3a), 148.67 (C-7a) ppm, assigned through HSQC and the following ${ }^{1} \mathrm{H} /{ }^{13} \mathrm{C}$ HMBC ${ }^{3} J$ and ${ }^{2} J$ interactions. ${ }^{3} \mathrm{~J}: 2-\mathrm{H} \rightarrow$ both $1-\mathrm{CH}_{3}$, pseudoequatorial 3-H $\rightarrow \mathrm{C}-1$ (strong) and $\mathrm{C}-7$ a (strong), both $1-\mathrm{CH}_{3} \rightarrow \mathrm{C}-2$ and $\mathrm{C}-7 \mathrm{a}, \mathrm{C}-3 \mathrm{a} \rightarrow 5-\mathrm{H}$ and $7-\mathrm{H}, \mathrm{C}-4 \rightarrow 6-\mathrm{H}, \mathrm{C}-5$ $\rightarrow 7-\mathrm{H}, \mathrm{C}-6 \rightarrow 4-\mathrm{H}, \mathrm{C}-7 \rightarrow 5-\mathrm{H}, \mathrm{C}-7 \mathrm{a} \rightarrow 4-\mathrm{H}$ and 6-H, uncertain pseudoaxial $1-\mathrm{CH}_{3} \rightarrow$ pseudoequatorial $1-\mathrm{CH}_{3}$, uncertain pseudoequatorial 1- $\mathrm{CH}_{3} \rightarrow$ pseudoaxial $1-\mathrm{CH}_{3} ;{ }^{2} \mathrm{~J}: 3-\mathrm{H} \rightarrow \mathrm{C}-3 \mathrm{a}$ but not $\mathrm{C}-2$, both $1-\mathrm{CH}_{3} \rightarrow \mathrm{C}-1$; MS (EI) $m / z$ (\%): 225.008 (52, $\left.\mathrm{C}_{11} \mathrm{H}_{12}{ }^{81} \mathrm{Br}^{+}, \mathrm{M}-\mathrm{Br}^{-}\right), 223.006\left(62, \mathrm{C}_{11} \mathrm{H}_{12}{ }^{79} \mathrm{Br}^{+}, \mathrm{M}-\mathrm{Br}^{-}\right)$; HRMS (EI) $m / z$ : $223.0164\left(\mathrm{C}_{11} \mathrm{H}_{12}{ }^{79} \mathrm{Br}^{+}, \mathrm{M}-\mathrm{Br}^{-}\right.$, calcd 223.0117), no $\mathrm{M}^{+}$peak.

3-Bromo-1,1-dimethylindene (3). A crude sample of the 9:1 mixture of trans $\mathbf{- 1}$ and cis-1 (23.0 g, max. $75 \mathrm{mmol})$ was added to a saturated solution of solid $\mathrm{KOH}(30.0 \mathrm{~g}, 833 \mathrm{mmol})$ in ethanol $(190 \mathrm{~mL})$ and heated to $50{ }^{\circ} \mathrm{C}$ for 4 hours. After cautious removal of some ethanol (ca. $130 \mathrm{~mL}$ ) in vacuo, the residue was poured into distilled water (ca. $400 \mathrm{~mL}$ ) and extracted with $\mathrm{Et}_{2} \mathrm{O}(4 \times 100 \mathrm{~mL})$. The combined $\mathrm{Et}_{2} \mathrm{O}$ extracts were washed with distilled water until neutral, dried over $\mathrm{CaCl}_{2}$, concentrated, and distilled to yield a pure 92:8 mixture (11.19 g, $\geq 67 \%$ ) of 3- and 2-bromo-1,1-dimethylindene (3 and 4) with bp $115-117^{\circ} \mathrm{C} / 12$ Torr.

${ }^{1} \mathrm{H} \mathrm{NMR}$ of $3\left(\mathrm{CDCl}_{3}, 400 \mathrm{MHz}\right) \delta 1.32\left(\mathrm{~s}, 6 \mathrm{H}, 2 \times 1-\mathrm{CH}_{3}\right)$, $6.46(\mathrm{~s}, 1 \mathrm{H}, 2-\mathrm{H}), 7.25\left(\mathrm{tm},{ }^{3} J=7 \mathrm{~Hz}, 1 \mathrm{H}, 6-\mathrm{H}\right), 7.28(\mathrm{~m}, 1 \mathrm{H}$, 7-H), $7.30(\mathrm{~m}, 1 \mathrm{H}, 5-\mathrm{H}), 7.33\left(\mathrm{dm},{ }^{3} J=7.5 \mathrm{~Hz}, 1 \mathrm{H}, 4-\mathrm{H}\right) \mathrm{ppm}$, assigned through HSQC and ${ }^{1} \mathrm{H} /{ }^{13} \mathrm{C} \mathrm{HMBC}$ (see below); ${ }^{13} \mathrm{C} \mathrm{NMR}\left(\mathrm{CDCl}_{3}, 100.6 \mathrm{MHz}\right) \delta 24.17\left(2 \times 1-\mathrm{CH}_{3}\right), 49.97$ (C-1), 118.19 (C-3), 120.48 (C-4), 120.81 (C-7), 126.41 (C-6), 126.87 (C-5), 140.84 (C-3a), 145.13 (C-2), 151.74 (C-7a) ppm, assigned through HSQC and the following ${ }^{1} \mathrm{H} /{ }^{13} \mathrm{C}$ HMBC ${ }^{3} J$ interactions. 1- $\mathrm{CH}_{3} \rightarrow \mathrm{C}-2$ and $\mathrm{C}-7 \mathrm{a}, 2-\mathrm{H} \rightarrow \mathrm{C}-3 \mathrm{a}$ and $\mathrm{C}-7 \mathrm{a}$, $\mathrm{C}-3 \rightarrow 4-\mathrm{H} \rightarrow \mathrm{C}-6, \mathrm{C}-3 \mathrm{a} \rightarrow 7-\mathrm{H} \rightarrow \mathrm{C}-5, \mathrm{C}-4 \rightarrow 6-\mathrm{H}, \mathrm{C}-7 \rightarrow$ 5-H, C-7a $\rightarrow$ 2-/4-/6-H; Anal. calcd for $\mathrm{C}_{11} \mathrm{H}_{11} \mathrm{Br}$ (223.13): C, 59.22; H, 4.97; found [18]: C, 58.79; $\mathrm{H}, 4.91$. The alternative $\mathrm{HBr}$ elimination with $\mathrm{KO} t$-Bu was rapid and exothermic in diglyme as the solvent.

2-Bromo-1,1-dimethylindene (4). A sample of contaminated 2,3-dibromo-1,1-dimethylindene (7,8.43 g, $27.7 \mathrm{mmol})$ in pentane $(5.0 \mathrm{~mL})$ was treated with $n$-BuLi (ca. $40 \mathrm{mmol}$ ) in hexane $(35 \mathrm{~mL})$ at $-70{ }^{\circ} \mathrm{C}$ under argon gas cover. Since this reaction was run in an acyclic, saturated hydrocarbon as the solvent (no cyclopentane, no benzene), a voluminous precipitate began to emerge slowly at $\mathrm{rt}$ within ca. one hour. When this colorless powder of 2-bromo-3-lithio-1,1-dimethylindene (10) had settled after 20 hours at $\mathrm{rt}$, the supernatant was withdrawn by syringe, and the residue was washed with dry pentane $(3 \times 15 \mathrm{~mL})$. This purified, solid material was suspended in pentane at $-70{ }^{\circ} \mathrm{C}$ under argon gas and quenched with methanol $(2.0 \mathrm{~mL})$. After dilution with water and $\mathrm{Et}_{2} \mathrm{O}$, the aqueous layer was extracted with $\mathrm{Et}_{2} \mathrm{O}(2 \times)$. The combined $\mathrm{Et}_{2} \mathrm{O}$ phases were washed with water until neutral and dried over $\mathrm{Na}_{2} \mathrm{SO}_{4}$. The crude material contained 4 and 1,1-dimethylindene (2, 77:23) without any other indene derivative. Pure 4 (2.10 g, $34 \%)$ distilled at $101-103{ }^{\circ} \mathrm{C} / 12$ Torr. ${ }^{1} \mathrm{H}$ NMR $\left(\mathrm{CDCl}_{3}\right.$, $400 \mathrm{MHz}) \delta 1.25\left(\mathrm{~s}, 6 \mathrm{H}, 2 \times 1-\mathrm{CH}_{3}\right), 6.75(\mathrm{~s}, 1 \mathrm{H}, 3-\mathrm{H}), 7.15$ $\left(\mathrm{tm},{ }^{3} J=7.5 \mathrm{~Hz}, 1 \mathrm{H}, 6-\mathrm{H}\right), 7.18\left(\mathrm{tm},{ }^{3} J=7.5 \mathrm{~Hz}, 1 \mathrm{H}, 5-\mathrm{H}\right)$, $7.23\left(\mathrm{dm},{ }^{3} J=7.5 \mathrm{~Hz}, 1 \mathrm{H}, 4-\mathrm{H}\right), 7.27\left(\mathrm{dm},{ }^{3} J=\right.$ ca. $7 \mathrm{~Hz}, 1 \mathrm{H}$, 7-H) ppm, assigned through comparisons with 3 and 7, HSQC and ${ }^{1} \mathrm{H} /{ }^{13} \mathrm{C} \mathrm{HMBC}$ (see below), and the NOESY correlation $1-\mathrm{CH}_{3} \leftrightarrow 7-\mathrm{H} ;{ }^{1} \mathrm{H} \mathrm{NMR}\left(\mathrm{D}_{3} \mathrm{C}-\mathrm{C} \equiv \mathrm{N}, 200 \mathrm{MHz}\right) \delta 1.25(\mathrm{~s}, 6 \mathrm{H}$, $\left.2 \times 1-\mathrm{CH}_{3}\right), 6.89(\mathrm{~s}, 1 \mathrm{H}, 3-\mathrm{H}) \mathrm{ppm} ;{ }^{13} \mathrm{C} \mathrm{NMR}\left(\mathrm{CDCl}_{3}\right.$, $100.6 \mathrm{MHz}) \delta 23.94\left(2 \times 1-\mathrm{CH}_{3}\right), 52.05(\mathrm{C}-1), 120.48(\mathrm{C}-4)$, 121.51 (C-7), 125.11 (C-6), 126.70 (C-5), 128.99 (C-3), 139.86 (C-2), 141.07 (C-3a), 151.66 (C-7a) ppm, assigned through HSQC, comparison with 7, and the following ${ }^{1} \mathrm{H} /{ }^{13} \mathrm{C} \mathrm{HMBC}^{3} J$ and ${ }^{2} \mathrm{~J}$ interactions. ${ }^{3} \mathrm{~J}: 1-\mathrm{CH}_{3} \rightarrow 1-\mathrm{CH}_{3}, 1-\mathrm{CH}_{3} \rightarrow \mathrm{C}-2$ and 
$\mathrm{C}-7 \mathrm{a}, 3-\mathrm{H} \rightarrow \mathrm{C}-1$ and $\mathrm{C}-7 \mathrm{a}, 7-\mathrm{H} \rightarrow \mathrm{C}-3 \mathrm{a}$ and C-5, C-6 $\rightarrow$ 4-H; ${ }^{2} \mathrm{~J}: 1-\mathrm{CH}_{3} \rightarrow \mathrm{C}-1,3-\mathrm{H} \rightarrow \mathrm{C}-3 \mathrm{a}$; MS (EI, $\left.70 \mathrm{eV}, 80{ }^{\circ} \mathrm{C}\right) \mathrm{m} / \mathrm{z}(\%)$ 224 and $222\left(2 \times 11, \mathrm{M}^{+}\right), 143\left(100, \mathrm{M}-\mathrm{Br}^{-}\right), 128\left(56, \mathrm{M}^{+}-\right.$ $\mathrm{CH}_{3} \mathrm{Br}$ ); HRMS (EI) $m / z 224.0026\left(\mathrm{C}_{11} \mathrm{H}_{11}{ }^{81} \mathrm{Br}^{+}, \mathrm{M}^{+}\right)$, $222.0045\left(\mathrm{C}_{11} \mathrm{H}_{11}{ }^{79} \mathrm{Br}^{+}, \mathrm{M}^{+}\right)$; Anal. calcd for $\mathrm{C}_{11} \mathrm{H}_{11} \mathrm{Br}$ (223.13): C, 59.22; H, 4.97; found: C, $60.55 \mathrm{H}, 4.97$.

2,3,3-Tribromo-1,1-dimethylindane (5): This thermolabile adduct of 3-bromo-1,1-dimethylindene (3) and elemental bromine (see 7) was not purified but recognized through its ${ }^{1} \mathrm{H}$ NMR chemical shifts and its thermolysis product 7 . ${ }^{1} \mathrm{H} \mathrm{NMR}\left(\mathrm{CDCl}_{3}, 200 \mathrm{MHz}\right) \delta 1.36\left(\mathrm{~s}, 3 \mathrm{H}, 1-\mathrm{CH}_{3}\right), 1.39$ (s, 3H, $\left.1-\mathrm{CH}_{3}\right), 4.78$ (s, 1H, 2-H) ppm; ${ }^{1} \mathrm{H} \mathrm{NMR}\left(\mathrm{CCl}_{4}, 200 \mathrm{MHz}\right) \delta$ $1.34\left(\mathrm{~s}, 3 \mathrm{H}, 1-\mathrm{CH}_{3}\right), 1.37\left(\mathrm{~s}, 3 \mathrm{H}, 1-\mathrm{CH}_{3}\right), 4.69(\mathrm{~s}, 1 \mathrm{H}, 2-\mathrm{H})$ ppm.

2,2,3-Tribromo-1,1-dimethylindane (6): A crude sample of 2-bromo-1,1-dimethylindene (4, ca. $3 \mathrm{mmol})$ in $\mathrm{CCl}_{4}(4 \mathrm{~mL})$ was overtitrated with elemental bromine in $\mathrm{CCl}_{4}$ solution at $\mathrm{rt}$. After 3 hours, the excess of bromine was swept off in a stream of $\mathrm{N}_{2}$ gas or destroyed with aqueous sodium sulfite. Almost pure 6 distilled at $157-161{ }^{\circ} \mathrm{C}$ (bath temp.)/3 mbar as a nearly colorless, viscos liquid (528 mg, $1.38 \mathrm{mmol}) .{ }^{1} \mathrm{H} \mathrm{NMR}\left(\mathrm{CDCl}_{3}\right.$, $400 \mathrm{MHz}) \delta 1.48\left(\mathrm{~s}, 3 \mathrm{H}\right.$, pseudoaxial 1- $\left.\mathrm{CH}_{3}\right), 1.72(\mathrm{~s}, 3 \mathrm{H}$, pseudoequatorial 1- $\left.\mathrm{CH}_{3}\right), 5.94(\mathrm{~s}, 1 \mathrm{H}, 3-\mathrm{H}), 7.18\left(\mathrm{dm},{ }^{3} J=7.4\right.$ $\mathrm{Hz}, 1 \mathrm{H}, 7-\mathrm{H}), 7.31\left(\mathrm{td},{ }^{3} J=7.4 \mathrm{~Hz},{ }^{4} J=1.3 \mathrm{~Hz}, 1 \mathrm{H}, 5-\mathrm{H}\right), 7.35$ (td, $\left.{ }^{3} J=7.2 \mathrm{~Hz}, 1 \mathrm{H}, 6-\mathrm{H}\right), 7.42\left(\mathrm{dm},{ }^{3} J=7 \mathrm{~Hz}, 1 \mathrm{H}, 4-\mathrm{H}\right) \mathrm{ppm}$, assigned through HMBC (see below) and the NOESY correlations $4-\mathrm{H} \leftrightarrow$ pseudoaxial $3-\mathrm{H} \leftrightarrow$ pseudoaxial 1- $\mathrm{CH}_{3} \leftrightarrow 7-\mathrm{H} \leftrightarrow$ pseudoequatorial $1-\mathrm{CH}_{3} ;{ }^{13} \mathrm{C} \mathrm{NMR}\left(\mathrm{CDCl}_{3}, 100.6 \mathrm{MHz}\right) \delta$ 27.49 (slighly broadened pseudoequatorial 1- $\mathrm{CH}_{3}$ ), 27.84 (pseudoaxial 1- $\mathrm{CH}_{3}$ ), $55.18(\mathrm{C}-1), 63.97(\mathrm{C}-3), 84.42$ (C-2), 122.45 (C-7), 125.64 (C-4), 128.03 (C-5), 129.77 (C-6), 137.56 (C-3a), 146.18 (C-7a) ppm, assigned through HSQC and the following ${ }^{3} J$ and ${ }^{2} J$ HMBC cross peaks. ${ }^{3} J$ : both $1-\mathrm{CH}_{3} \rightarrow \mathrm{C}-2$ and $\mathrm{C}-7 \mathrm{a}, 3-\mathrm{H} \rightarrow \mathrm{C}-4$ and $\mathrm{C}-7 \mathrm{a}$ (but not $\mathrm{C}-1$ since $3-\mathrm{H}$ is pseudoaxial), $4-\mathrm{H} \rightarrow \mathrm{C}-6$ and $\mathrm{C}-7 \mathrm{a}, 7-\mathrm{H} \rightarrow \mathrm{C}-3 \mathrm{a}$ and $\mathrm{C}-5, \mathrm{C}-4$ $\rightarrow$ 6-H, C-3a $\rightarrow 5-\mathrm{H} ;{ }^{2} \mathrm{~J}$ : both $1-\mathrm{CH}_{3} \rightarrow \mathrm{C}-1,3-\mathrm{H} \rightarrow \mathrm{C}-3 \mathrm{a}$; HRMS and MS (EI) $m / z(\%) 385.8143\left(0.1, \mathrm{C}_{11} \mathrm{H}_{11}{ }^{81} \mathrm{Br}_{3}{ }^{+}\right.$, $\left.\mathrm{M}^{+}\right), 383.8302\left(0.4, \mathrm{C}_{11} \mathrm{H}_{11}{ }^{79} \mathrm{Br}^{81} \mathrm{Br}_{2}{ }^{+}, \mathrm{M}^{+}\right), 381.8358(0.5$, $\left.\mathrm{C}_{11} \mathrm{H}_{11}{ }^{79} \mathrm{Br}_{2}{ }^{81} \mathrm{Br}^{+}, \mathrm{M}^{+}\right), 379.8274\left(0.3, \mathrm{C}_{11} \mathrm{H}_{11}{ }^{79} \mathrm{Br}_{3}{ }^{+}, \mathrm{M}^{+}\right)$, $304.98\left(12, \mathrm{C}_{11} \mathrm{H}_{11}{ }^{81} \mathrm{Br}_{2}{ }^{+}, \mathrm{M}-\mathrm{Br}^{-}\right), 302.98$ (26, $\mathrm{C}_{11} \mathrm{H}_{11}{ }^{79} \mathrm{Br}^{81} \mathrm{Br}^{+}, \mathrm{M}-\mathrm{Br}^{-}$), $300.98\left(13, \mathrm{C}_{11} \mathrm{H}_{11}{ }^{79} \mathrm{Br}_{2}^{+}, \mathrm{M}-\right.$ $\mathrm{Br}^{-}$).

2,3-Dibromo-1,1-dimethylindene (7): a) From 3-bromo-1,1dimethylindene (3): A solution of $\mathbf{3}$ (4.08 g, $18.3 \mathrm{mmol})$ in $\mathrm{CCl}_{4}$ $(10 \mathrm{~mL})$ was cooled and stirred in an ice-bath and titrated with elemental bromine $(2.92 \mathrm{~g}, 18.3 \mathrm{mmol})$ in $\mathrm{CCl}_{4}$. The initially instantaneous decolorization of bromine became progressively slower with a half-reaction time of roughly 2 min toward the end. After 2 hours at $\mathrm{rt}$, the solution contained some product 7 and mainly 2,3,3-tribromo-1,1-dimethylindane (5). Upon $\mathrm{CCl}_{4}$ evaporation in vacuo up to $80{ }^{\circ} \mathrm{C}$ (darkening), the primary product 5 became thermally converted into 7 during distillation that yielded 7 (4.42 g, 80\%) as a colorless, slightly light-sensitive liquid; analytically pure 7 had bp $144-146{ }^{\circ} \mathrm{C} / 13$ Torr. ${ }^{1} \mathrm{H}$ NMR $\left(\mathrm{CDCl}_{3}, 400 \mathrm{MHz}\right) \delta 1.31\left(\mathrm{~s}, 6 \mathrm{H}, 2 \times 1-\mathrm{CH}_{3}\right), 7.26\left(\mathrm{~m},{ }^{3} \mathrm{~J}=\right.$ $7.5 \mathrm{~Hz}, 1 \mathrm{H}, 6-\mathrm{H}), 7.30(\mathrm{~m}, 1 \mathrm{H}, 5-\mathrm{H}), 7.31$ (m, 1H, 7-H), 7.36 (dm, $\left.{ }^{3} J=7.5 \mathrm{~Hz}, 1 \mathrm{H}, 4-\mathrm{H}\right) \mathrm{ppm}$, assigned through HSQC, comparison with 3 , and the NOESY correlation $1-\mathrm{CH}_{3} \leftrightarrow 7-\mathrm{H}$; ${ }^{13} \mathrm{C} \mathrm{NMR}\left(\mathrm{CDCl}_{3}, 100.6 \mathrm{MHz}\right) \delta 24.2\left(2 \times 1-\mathrm{CH}_{3}\right), 52.6(\mathrm{C}-1)$, 120.0 (C-3), 120.3 (C-4), 121.3 (C-7), 126.4 (C-6), 127.2 (C-5), 138.9 (C-2), 139.9 (C-3a), 150.0 (C-7a) ppm, assigned through HSQC, comparison with 3 , and the following ${ }^{3} J$ and ${ }^{2} J$ HMBC cross peaks. ${ }^{3} \mathrm{~J}: 1-\mathrm{CH}_{3} \rightarrow \mathrm{C}-2$ and $\mathrm{C}-7 \mathrm{a}, 4-\mathrm{H} \rightarrow \mathrm{C}-3$ and $\mathrm{C}-6$ and C-7a, 7-H $\rightarrow \mathrm{C}-3 \mathrm{a}$ and $\mathrm{C}-5, \mathrm{C}-4 \rightarrow 6-\mathrm{H}, \mathrm{C}-7 \rightarrow 5-\mathrm{H} ;{ }^{2} \mathrm{~J}$ : $1-\mathrm{CH}_{3} \rightarrow \mathrm{C}-1$; HRMS (EI) $m / z$ (\%) 303.9135 (14, $\mathrm{C}_{11} \mathrm{H}_{10}{ }^{81} \mathrm{Br}_{2}{ }^{+}$, calcd 303.9103, $\left.\mathrm{M}^{+}\right), 301.9119$ (25, $\mathrm{C}_{11} \mathrm{H}_{10}{ }^{79} \mathrm{Br}^{81} \mathrm{Br}^{+}$, calcd 301.9123, $\left.\mathrm{M}^{+}\right), 299.9146$ (14, $\mathrm{C}_{11} \mathrm{H}_{10}{ }^{79} \mathrm{Br}_{2}{ }^{+}$, calcd 299.9144, $\mathrm{M}^{+}$), $222.9936(83$, $\left.\mathrm{C}_{11} \mathrm{H}_{10}{ }^{81} \mathrm{Br}^{+}, \mathrm{M}-\mathrm{Br}^{-}\right), 220.9974\left(77, \mathrm{C}_{11} \mathrm{H}_{10}{ }^{79} \mathrm{Br}^{+}, \mathrm{M}-\mathrm{Br}^{-}\right)$; Anal. calcd for $\mathrm{C}_{11} \mathrm{H}_{10} \mathrm{Br}_{2}$ (302.0): C, 43.75; H, 3.34; $\mathrm{Br}, 52.92$; found: $\mathrm{C}, 44.06 ; \mathrm{H}, 3.42 ; \mathrm{Br}, 52.00$.

b) From 2-bromo-1,1-dimethylindene (4) via 2,2,3-tribromo1,1-dimethylindane (6): A small sample (44 mg, $0.11 \mathrm{mmol}$ ) of distilled tribromide 6 (obtained as above from 4 and containing no trace of 7) in $\mathrm{CCl}_{4}$ was placed in an NMR tube $(5 \mathrm{~mm})$ and treated with an excess of solid $\mathrm{KO} t$ - $\mathrm{Bu}$, which consumed 6 within less than 2 hours at rt. Aqueous work-up with $\mathrm{Et}_{2} \mathrm{O}$ afforded the dibromide $7(29 \mathrm{mg}, 87 \%)$ as the only product (hence, no $\mathrm{S}_{\mathrm{N}} 2$ reaction by $\mathrm{KO} t-\mathrm{Bu}$ ). $\mathrm{NEt}_{3}$ as the base in place of $\mathrm{KO} t-\mathrm{Bu}$ required 12 days at $\mathrm{rt}$.

c) From 1,1-dimethylindane (9): A mixture of $N$-bromosuccinimide (NBS, $7.13 \mathrm{~g}, 40 \mathrm{mmol}), 1$,1-dimethylindane (9, $1.46 \mathrm{~g}$, $10 \mathrm{mmol}$, see Supporting Information File 1), and $\mathrm{CCl}_{4}(50 \mathrm{~mL})$ was treated with azobis(isobutyronitrile) $(40 \mathrm{mg}$ ) and warmed slowly up to $85^{\circ} \mathrm{C}$. After $30 \mathrm{~min}$ of vived refluxing, the dark red suspension showed traces of elemental bromine in the gas phase and was cooled in an ice bath (15 min). A ${ }^{1} \mathrm{H}$ NMR spectrum of the solution revealed that the starting material 9 was completely consumed and that a mixture containing three gemdimethyl compounds had been generated: 2,3-dibromo-1,1-dimethylindene $(7,76 \%), 1$ (1\%, trans/cis ca. 3:2), and an unknown side-product (20\%). The suspension was filtered, and the undissolved portion was washed with $\mathrm{CCl}_{4}(2 \times 5 \mathrm{~mL})$, affording a colorless, powdery mixture of NBS and succinimide ( $4: 36$ by ${ }^{1} \mathrm{H}$ NMR). The dark red $\mathrm{CCl}_{4}$ filtrate became colorless on shaking with an aqueous solution of sodium sulfite (at least $0.6 \mathrm{~g}$ ) and was washed with distilled water $(10 \mathrm{~mL})$, 
then dried through stirring with granulated $\mathrm{CaCl}_{2}$ (30 min). After removal of $\mathrm{CaCl}_{2}$, the colorless solution became violet on stirring with a sufficient amount of solid $\mathrm{KO} t$ - $\mathrm{Bu}(2.6 \mathrm{~g})$ for $30 \mathrm{~min}$, which destroyed the two dibromides 1 and other small contaminations. The $\mathrm{CCl}_{4}$ solution was shaken with $\mathrm{H}_{2} \mathrm{O}$ $(10 \mathrm{~mL})$, aqueous $\mathrm{HCl}(2 \mathrm{M}, 10 \mathrm{~mL})$, and $\mathrm{H}_{2} \mathrm{O}$ until neutral, then dried as above with $\mathrm{CaCl}_{2}$ (35 min). Evaporation of $\mathrm{CCl}_{4}$ and subsequent distillation in vacuo furnished the colorless liquid 7 (1.35 g, 45\%).

\section{Supporting Information}

\section{Supporting Information File 1}

Alternative synthetic routes to 1,1-dimethylindene (2) and congeners; experimental procedures for $\mathbf{2}$,

1,1-dimehylindane (9), 3-methyl-1-phenylbutan-2-ol,

$N$-(1,1-dimethylindan-3-ylidene)hydrazine, and

$N, N^{\prime}$-bis(1,1-dimethylindan-3-ylidene)hydrazine.

[http://www.beilstein-journals.org/bjoc/content/

supplementary/1860-5397-12-113-S1.pdf]

\section{Acknowledgements}

This article is dedicated to Professor Manfred Heuschmann on the occasion of his retirement. Technical support of this research by the Organic Chemistry Division of the Department Chemie is gratefully acknowledged.

\section{References}

1. Brown, R. S. Acc. Chem. Res. 1997, 30, 131-137. doi:10.1021/ar960088e

2. Ruasse, M.-F. Adv. Phys. Org. Chem. 1993, 28, 207-291. doi:10.1016/S0065-3160(08)60183-5

3. Ruasse, M.-F. Acc. Chem. Res. 1990, 23, 87-93. doi:10.1021/ar00171a006

4. Heasley, G. E.; Bower, T. R.; Dougharty, K. W.; Easdon, J. C.; Heasley, V. L.; Arnold, S.; Carter, T. L.; Yaeger, D. B.; Gipe, B. T.; Shellhamer, D. F. J. Org. Chem. 1980, 45, 5150-5155. doi:10.1021/jo01313a025

5. Sternhell, S. Q. Rev., Chem. Soc. 1969, 23, 236-270. doi:10.1039/QR9692300236

6. Austin, R. A.; Lillya, C. P. J. Org. Chem. 1969, 34, 1327-1333. doi:10.1021/jo01257a027

7. Jönsson, N. A.; Kempe, T.; Mikiver, L.; Gahlin, K.; Sparf, B. Acta Pharm. Suec. 1981, 18, 349-372.

Chem. Abstr. 1982, 96, 122365a. See this for a substance proposed to be cis-1 (compound $\mathbf{3 3}$ therein) without any analytic evidence.

8. von Roman, U.; Ruhdorfer, J.; Knorr, R. Synthesis 1993, 985-992. doi:10.1055/s-1993-25986

This ascribed the cis-1 structure (compound "cis"-19 therein) erroneously to the presently assigned trans-1 isomer.

9. Reference [7] reported an even higher value of ${ }^{3} \mathrm{~J}(2-\mathrm{H}, 3-\mathrm{H})=10 \mathrm{~Hz}$ for a substance (compound $\mathbf{3 0}$ on pp 361-362 therein) that carried a $\left(\mathrm{CH}_{2}\right)_{4}$ bridge in place of the two $1-\mathrm{CH}_{3}$ groups of 1 .
10. Kong, J.; Galabov, B.; Koleva, G.; Zou, J.-J.; Schaefer, H. F., III; von Ragué Schleyer, P. Angew. Chem., Int. Ed. 2011, 50, 6809-6813. doi:10.1002/anie.201101852

See this for more recent evidence concerning well-known thermal ("base-free") $\mathrm{HBr}$ eliminations from - $\mathrm{CHBr}-\mathrm{CHBr}$-moieties.

11. Reference [7] mentioned that the alleged "cis" isomer (compound 33 therein) formed crude 3 (compound $\mathbf{3 7}$ on $\mathrm{p} 362$ therein) on treatment with $\mathrm{KO} t-\mathrm{Bu}$, which behavior equals that of our trans-1.

12. Tutar, A.; Cakmak, O.; Balci, M. Tetrahedron 2001, 57, 9759-9763. doi:10.1016/S0040-4020(01)00978-4

See this for a report of methyl-free 1,1,3,3-tetrabromo-and 1,1,2,3,3-pentabromoindenes undergoing thermal $\mathrm{HBr}$ eliminations at or above $120^{\circ} \mathrm{C}$.

13. Zhu, H.-T.; Ji, K.-G.; Yang, F.; Wang, L.-J.; Zhao, S.-C.; Ali, S.; Liu, X.-Y.; Liang, Y.-M. Org. Lett. 2011, 13, 684-687. doi:10.1021/ol1029194

14. Zhou, C.; Chen, X.; Lu, P.; Wang, Y. Tetrahedron 2012, 68, 2844-2850. doi:10.1016/j.tet.2012.01.093

15. Wittig, G.; Heyn, H. Chem. Ber. 1964, 97, 1609-1618. doi:10.1002/cber.19640970613

16. Beak, P.; Musick, T. J.; Chen, C.-W. J. Am. Chem. Soc. 1988, 110, 3538-3542. doi:10.1021/ja00219a031

17. Beak, P.; Chen, C.-W. Tetrahedron Lett. 1985, 26, 4979-4980. doi:10.1016/S0040-4039(01)80830-3

18. Reference [8] reported MS, IR, and UV data of $\mathbf{3}$ as listed for 3- (not "2-"!) bromo-1,1-dimethylindene (compound 11i on p 990 therein) that had been prepared through brominative deoxygenation of 1,1-dimethyl-3-indanone.

\section{License and Terms}

This is an Open Access article under the terms of the Creative Commons Attribution License (http://creativecommons.org/licenses/by/2.0), which permits unrestricted use, distribution, and reproduction in any medium, provided the original work is properly cited.

The license is subject to the Beilstein Journal of Organic Chemistry terms and conditions:

(http://www.beilstein-journals.org/bjoc)

The definitive version of this article is the electronic one which can be found at:

doi:10.3762/bjoc. 12.113 